\title{
SCHISTOSOMA MANSONI: EVOLUÇÃO DE VERMES ORIUNDOS DE CERCÁRIAS IRRADIADAS A NIVVEL DE SISTEMA PORTA, NO CAMUNDONGO.
}

\author{
Gileno de Sá Cardoso' e Paulo Marcos Zech Coelho2
}

\begin{abstract}
Oito grupos de camundongos albinos (Mus musculus), não isogênicos, foram infectados transcutaneamente com cerca de 450 cercárias (das cepas LE e SJ do S. mansoni), irradiadas com $3 \mathrm{Krad}, 20 \mathrm{Krad}$ e $40 \mathrm{Krad}$ de radiação gama proveniente de cobalto-60, e não irradiados (grupos-controle). Os vermes provenientes de cercárias irradiadas com 20 e $40 \mathrm{Krad}$ só foram encontrados em quantidades insignificantes no sistema porta. Verificou-se que os vermes irradiados com $3 \mathrm{Krad}$, que alcançom o sistema porta, mostram nítido retardo no desenvolvimento evolutivo quando comparados com os grupos-controles não irradiados. Os vermes da cepa $S J$ (irradiados ou não) têm evolução mais lenta do que os da cepa $L E$.
\end{abstract}

Palavras-chaves: Schistosoma mansoni. Cercárias irradiadas. Radiação gama. Schistograma.

Barbosa e cols ${ }^{1}$, com o objetivo de investigar quantitativamente $\mathrm{o}$ assincronismo que ocorre no desenvolvimento do Schistosoma mansoni, utilizaram pela primeira vez o método do schistograma, pelo qual se determinam as porcentagens relativas de vermes caracterizados morfologicamente, em seis estádios evolutivos diferentes, de acordo com o desenvolvimento do tubo digestivo desses vermes durante a sua evolução no sistema porta de camundongos.

No presente estudo, utilizou-se pela primeira vez o método do schistograma com a finalidade de quantificar as alterações devidas à radiação gama no processo evolutivo de vermes provenientes de cercárias irradiadas com 3, 20 e $40 \mathrm{Krad}$, recuperados do sistema porta de camundongos infectados transcutaneamente com cerca de 450 cercárias, das cepas LE e $\mathrm{SJ}$ do $S$. mansoni. Com isso, pretendeu-se observar se havia alteração no desenvolvimento evolutivo dos vermes, com relação à cepa do parasito e à dose de irradiação recebida.

\section{MATERIAL E MÉTODOS}

Hospedeiros e parasitos. Camundongos albinos (Mus musculus), não isogênicos, fêmeas, com cerca de 30 dias de nascidos, foram infectados transcutaneamente com cerca de 450 cercárias de $S$. mansoni

1. Departamento de Parasitologia, Universidade Federal de Sergipe, 2. Departamento de Parasitologia, Instituto de Ciências Biológicas (ICB) da Universidade Federa1 de Minas Gerais (UFMG)

Trabalho realizado pelo Grupo Interdepartamental de Estudos sobre Esquistossomose (GIDE) em colaboração com o Centro de Desenvolvimento da Tecnologia $\mathrm{Nu}$ clear (CDTN) e com as Empresas Nucleares Brasileiras S.A. (Nuclebrás). A poio financeiro do CNPq., FINEP e $\mathrm{CPq}$ - UFMG.

Recebido para publicação em 26/05/89. da cepa LE de Belo Horizonte mantida no GIDE em Biomphalaria glabrata há mais de 25 anos e da cepa SJ de São José dos Campos - SP mantida no ICB em B. glabrata com repassagens sucessivas em Biomphalaria tenagophila há mais de 10 anos.

Os planorbídeos foram infectados seguindo-se a técnica descrita por Pellegrino \& $\mathrm{Katz}^{4}$, nascidos e criados em laboratório, segundo técnica de Freitas ${ }^{3}$.

Irradiação das cercárias. Oito grupos experimentais foram definidos utilizando-se cercárias não irradiadas (grupos-controles) e irradiadas com $3 \mathrm{Krad}$, $20 \mathrm{Krad}$ e $40 \mathrm{Krad}$, das duas cepas.

As amostras de cercárias a serem irradiadas eram transportadas para o CDTN da Nuclebrás, onde eram expostas à radiação gama proveniente de bomba de cobalto- 60 , sendo a dose de irradiaçāo equivalente ao tempo de exposição das cercárias a essa fonte de radiação.

Infecção dos camundongos. Seguiu-se a técnica descrita por Barbosa e cols ${ }^{1}$.

Recuperação de vermes do sistema porta. Do 89 dia após a infecçāo até o último dia de observação de cada grupo 47. (grupos, controles), 90 \% (grupos de 3 $\mathrm{Krad}), 40$ (grupos de $20 \mathrm{Krad}$ ) e 11 . (grupos de 40 $\mathrm{Krad}$ ), para ambas as cepas, foram recuperados os vermes do sistema porta, de acordo com a técnica de Pellegrino \& Siqueira ${ }^{5}$.

Classificação dos vermes do sistema porta. Como era de interesse quantificar a evolução do $S$. mansoni em função do tempo, os vermes foram classificados em seis estádios evolutivos, de acordo com Barbosa e cols ${ }^{1}$ cuja classificação se baseia na forma dos cecos gástricos.

Análise dos resultados. $\mathrm{Na}$ análise estatística dos resultados foi utilizado o método da análise de variância, trabalhando-se com proporções baseadas no rendimento cercárias/vermes, ajustadas pelo método da transformação angular ou do arco-seno, de acordo com Snedecor \& Cochran ${ }^{6}$. 
Cardoso GS, Coelho PMZ. Schistosoma mansoni: evolucāo de vermes oriundos de cercarias irradiadas a nivel de sistema porta, no camundongo. Revista da Sociedade Brasileira de Medicina Tropical 22: 199-210, Out-Dez, 1989.

\section{RESULTADOS}

Nas Tabelas de 1 a 8 estão representados todos os valores do schistograma e as porcentagens médias de recuperação de parasitos do sistema porta oriundos de cercárias, das cepas LE e SJ do $S$. mansoni, não irradiadas e irradiadas com $3 \mathrm{Krad}, 20 \mathrm{Krad}$ e $40 \mathrm{Krad}$ de radiação gama proveniente de $\mathrm{Co}-60$.

As porcentagens médias de recuperação de parasitos do sistema porta são calculadas em relação à carga infectante, enquanto que os valores do schistograma são calculados em relação ao total de vermes recuperados do sistema porta.

Os resultados são a média de recuperação de parasitos obtida em seis camundongos sacrificados a cada dia dos experimentos, levando-se em conta os tempos de infecção.

Nas Figuras 1 e 2 estão representados os schistogramas obtidos a partir da recuperação de parasitos do sistema porta oriundos de cercárias, das cepas LE e SJ do $S$. mansoni, não irradiadas e irradiadas com $3 \mathrm{Krad}$ de radiação gama proveniente de Co-60.

A análise de variância desses resultados mostrou que houve uma diminuição estatisticamente significativa $(P>0,01)$ nas taxas de recuperação dos grupos de vermes irradiados com $3 \mathrm{Krad}$ em relação aos controles, de ambas as cepas. Observou-se também que houve um aumento estatisticamente significativo $(\mathrm{P}>0,01)$ nas taxas de recuperação dos estádios mais evoluídos da cepa LE, em relação aos da SJ, nos primeiros dias em que foram detectados no sistema porta.

Os vermes oriundos de cercárias, das cepas $L E$ e SJ do $S$. mansoni, irradiadas com $20 \mathrm{Krad}$ e $40 \mathrm{Krad}$ somente foram detectadas em quantidades residuais no sistema porta, conforme consta nas Tabelas 3 e 4 (cepa LE) e 7 e 8 (cepa SJ), não sendo por esse motivo feita a representação gráfica do schistograma para esses grupos de vermes.

\section{DISCUSSÃO}

O uso de cercárias irradiadas como modelo de imunização na esquistossomose tem sido extensamente feito em pesquisas recentes ${ }^{2}$.

Pela primeira vez foram quantificadas as alteraçōes no processo evolutivo das formas irradiadas de $S$. mansoni que alcançam o sistema porta. Para tal objetivo, foi utilizada a técnica do schistograma, visando investigar se havia diferenças no desenvolvimento evolutivo dos vermes no sistema porta, tanto

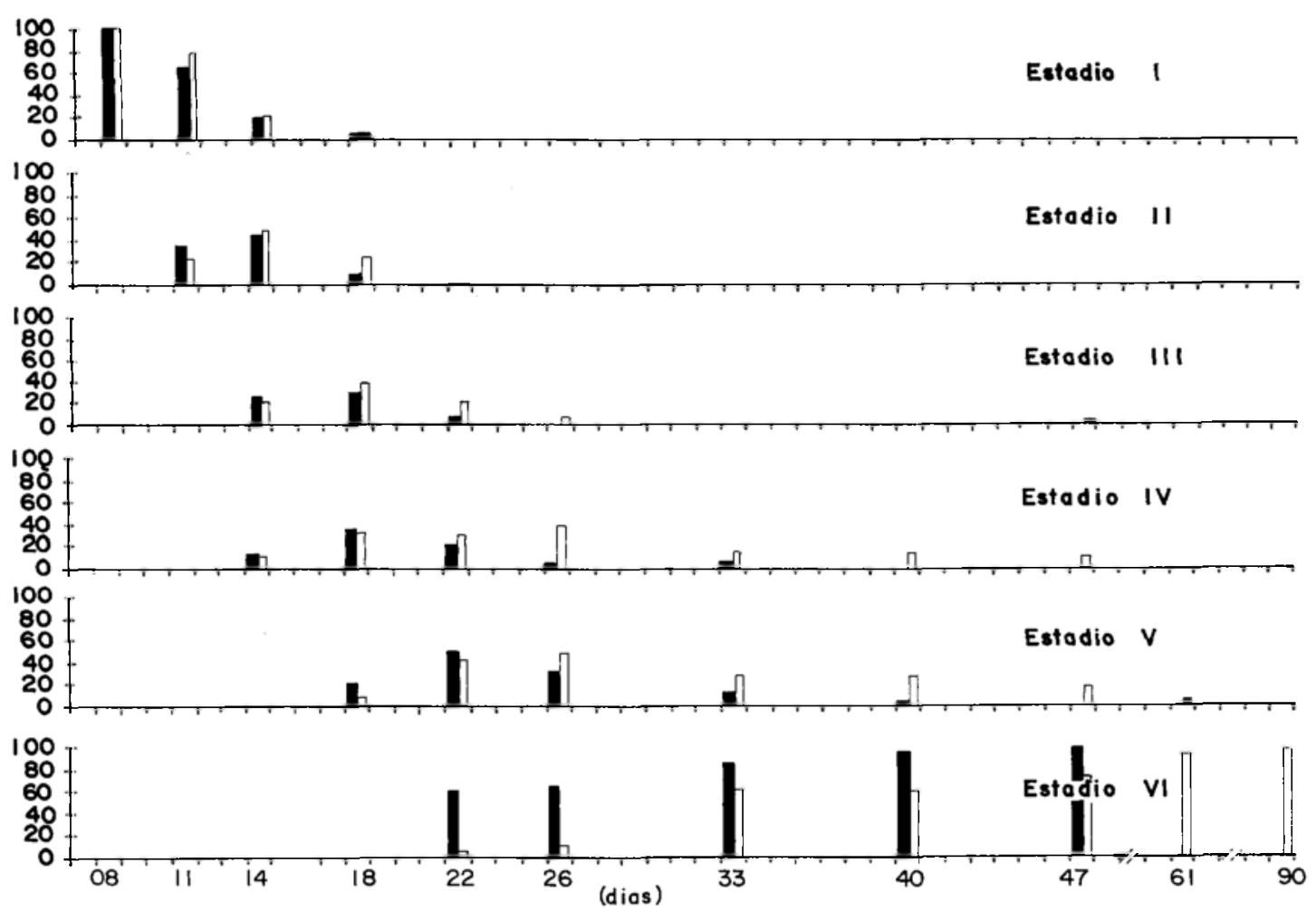

Figura 1 - Porcentagens médias de recuperação de vermes do sistema porta, da cepa LE do $S$. manson l, controles e irradiados com $3 \mathrm{Krad}$, nos diversos estádios evolutivos. Schistograma 1. 


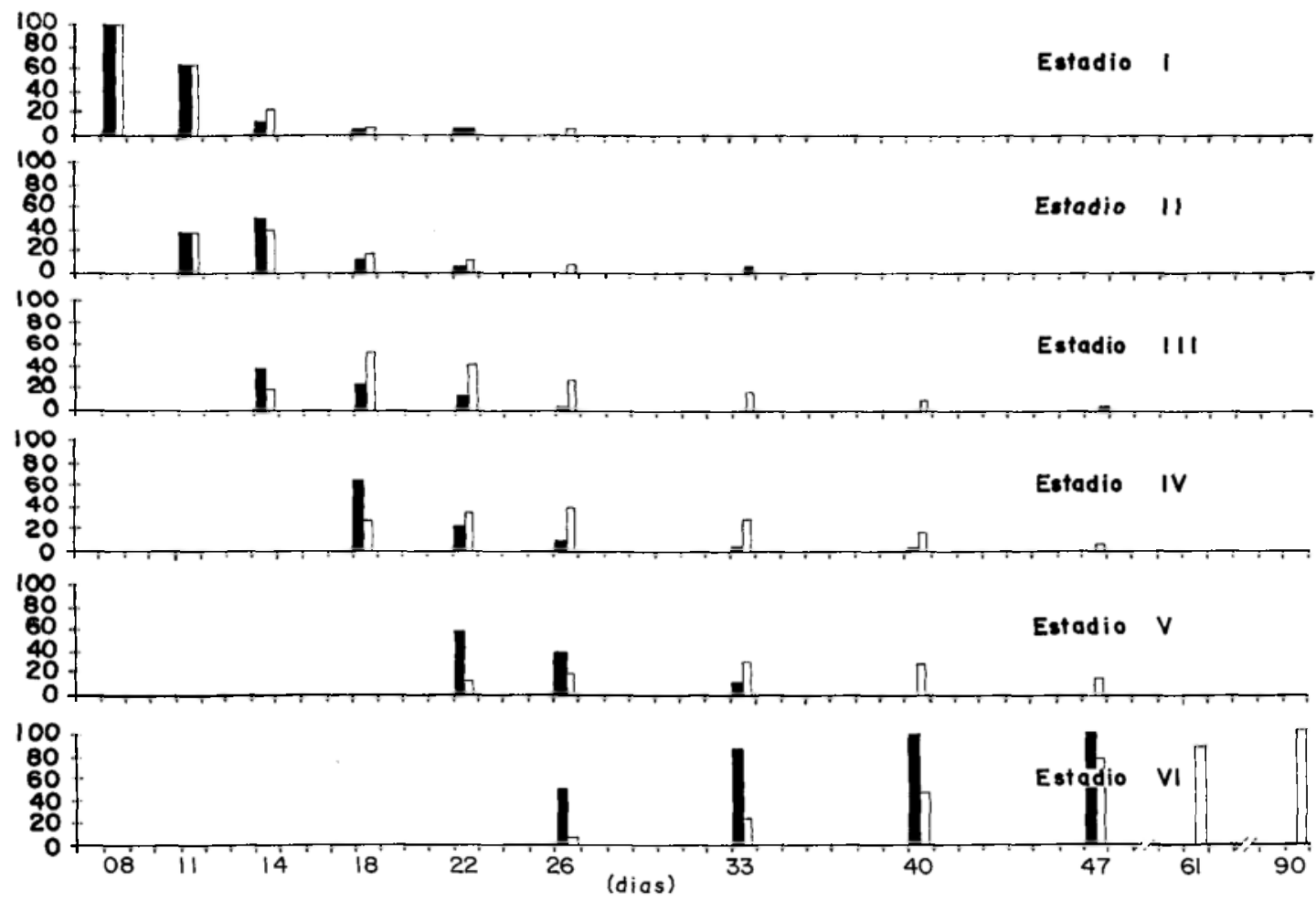

Figura 2 - Porcentagens médias de recuperação de vermes do sistema porta, da cepa SJ do $S$. mansoni, controles e irradiados com $3 \mathrm{Krad}$, nos diversos estádios evolutivos. Schistograma 2.

com relação às doses de irradiação recebidas como a cepa do parasito utilizada.

Os vermes irradiados com $20 \mathrm{Krad}$ foram detectados em quantidades residuais no sistema porta durante todo o período de observação, que foi do $8{ }^{\circ}$ ao 33. dia após a infecção, e evoluíram somente até o 3 ? estádio, em ambos os experimentos com as cepas LE e SJ (Tabela 3 para a cepa LE e Tabela 7 para a cepa SJ). Com relação aos vermes irradiados com $40 \mathrm{Krad}$, somente um verme (da cepa LE) foi detectado no sistema porta ( $80^{\circ}$ dia após a infecção) o qual era do 1 . estádio (Tabela 4 para a cepa LE e Tabela 8 para a cepa SJ). Por isso, não foram representadas nos schistogramas (Figura 1 para a cepa LE e Figura 2 para a cepa SJ) as porcentagens de recuperação desses parasitos.

Assim, a única dose que permitiu o desenvolvimento dos vermes até a fase adulta foi a de $3 \mathrm{Krad}$.

Analisando os resultados obtidos nas Figuras 1 e 2, verificou-se uma diferença estatisticamente signi- ficativa nas taxas de recuperação dos grupos de vermes irradiados com $3 \mathrm{Krad}$, em relação aos controles não irradiados, de ambas as cepas.

Pode-se concluir, então, que os vermes irradiados com 3 Krad tiveram uma evolução significativamente mais lenta do que os controles não irradiados, em ambas as cepas.

Com a finalidade de observar as diferenças na evolução das duas cepas de $S$. mansoni, irradiados e normais, as taxas de recuperação nos grupos irradiados com $3 \mathrm{Krad}$ e normais dos estádios evolutivos, considerando os primeiros dias de seu aparecimento no sistema porta, foram comparadas. Verificou-se, pela análise estatística, que as taxas de recuperação dos estágios mais evolutivos dos vermes, tanto irradiados com controles, da cepa LE foram significativamente maiores do que às relacionadas à cepa $\mathrm{SJ}$. Podese concluir que a cepa LE de Schistosoma mansoni, no camundongo, apresenta um desenvolvimento mais acelerado do que os da cepa $\mathbf{S J}$. 
Cardoso GS, Coelho PMZ. Schistosoma mansoni: evoluçào de vermes oriundos de cercarias irradiadas a nivel de sistema porta, no camundongo. Revista da Sociedade Brasileira de Medicina Tropical 22: 199-210, Out-Dez, 1989.

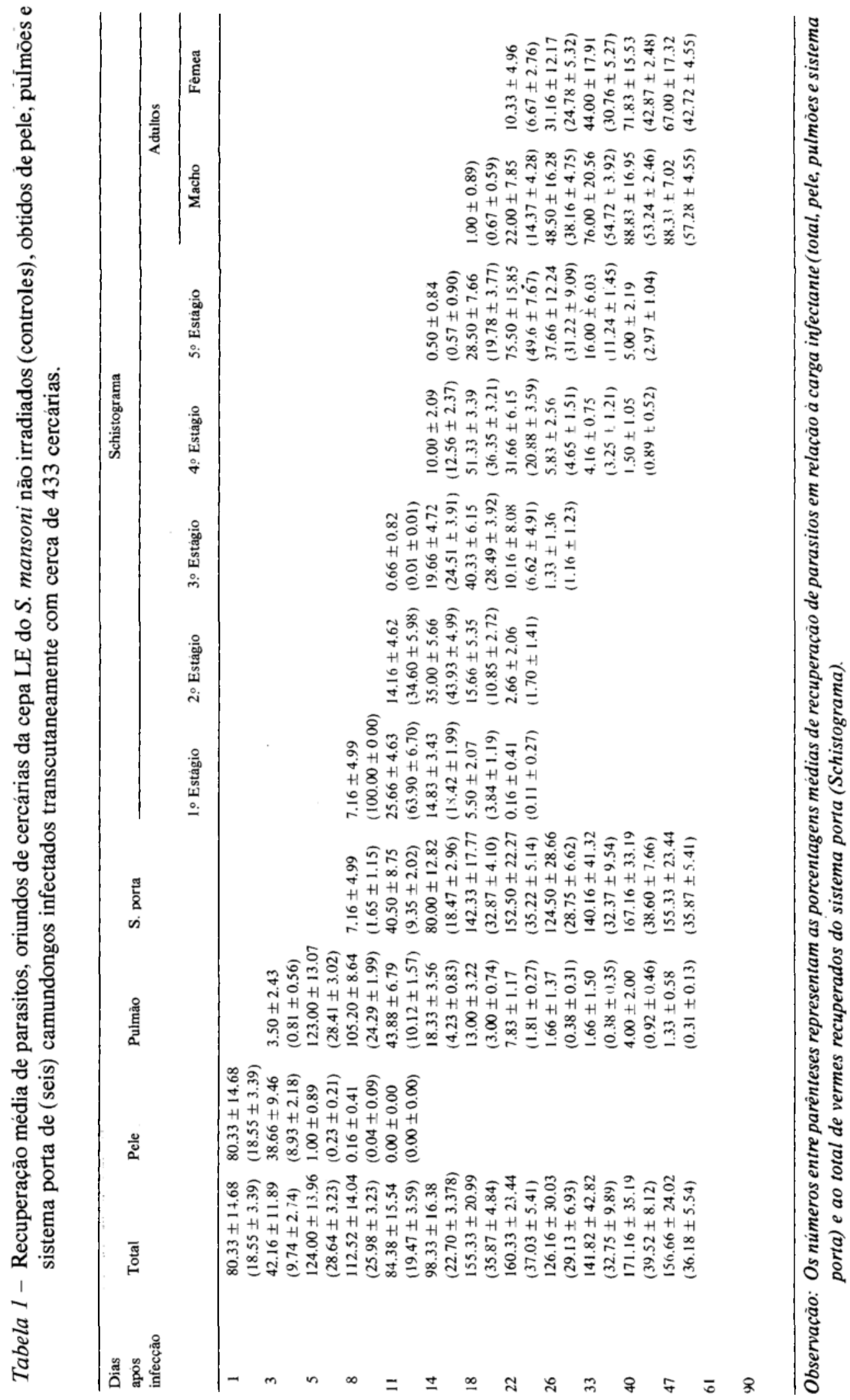




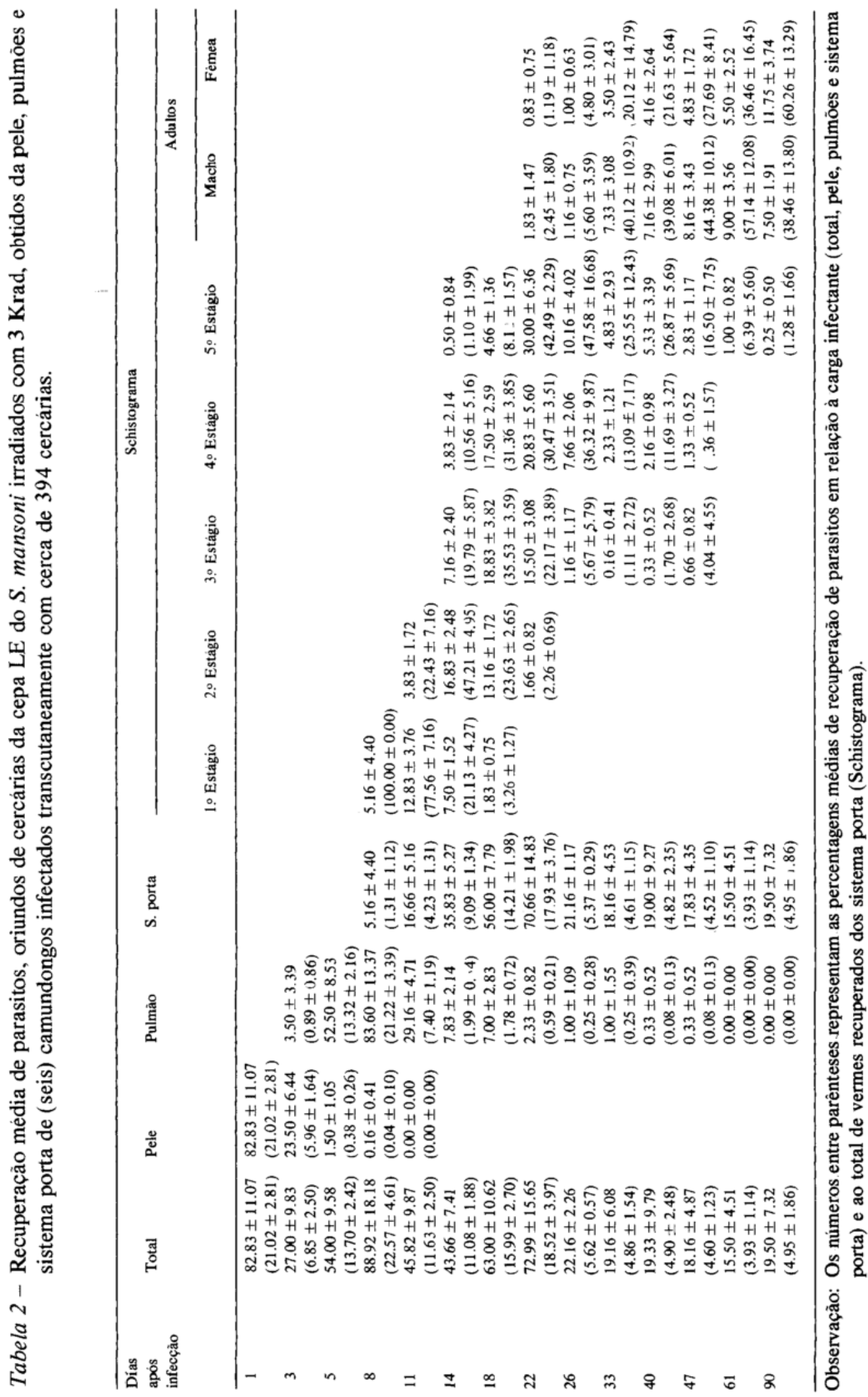




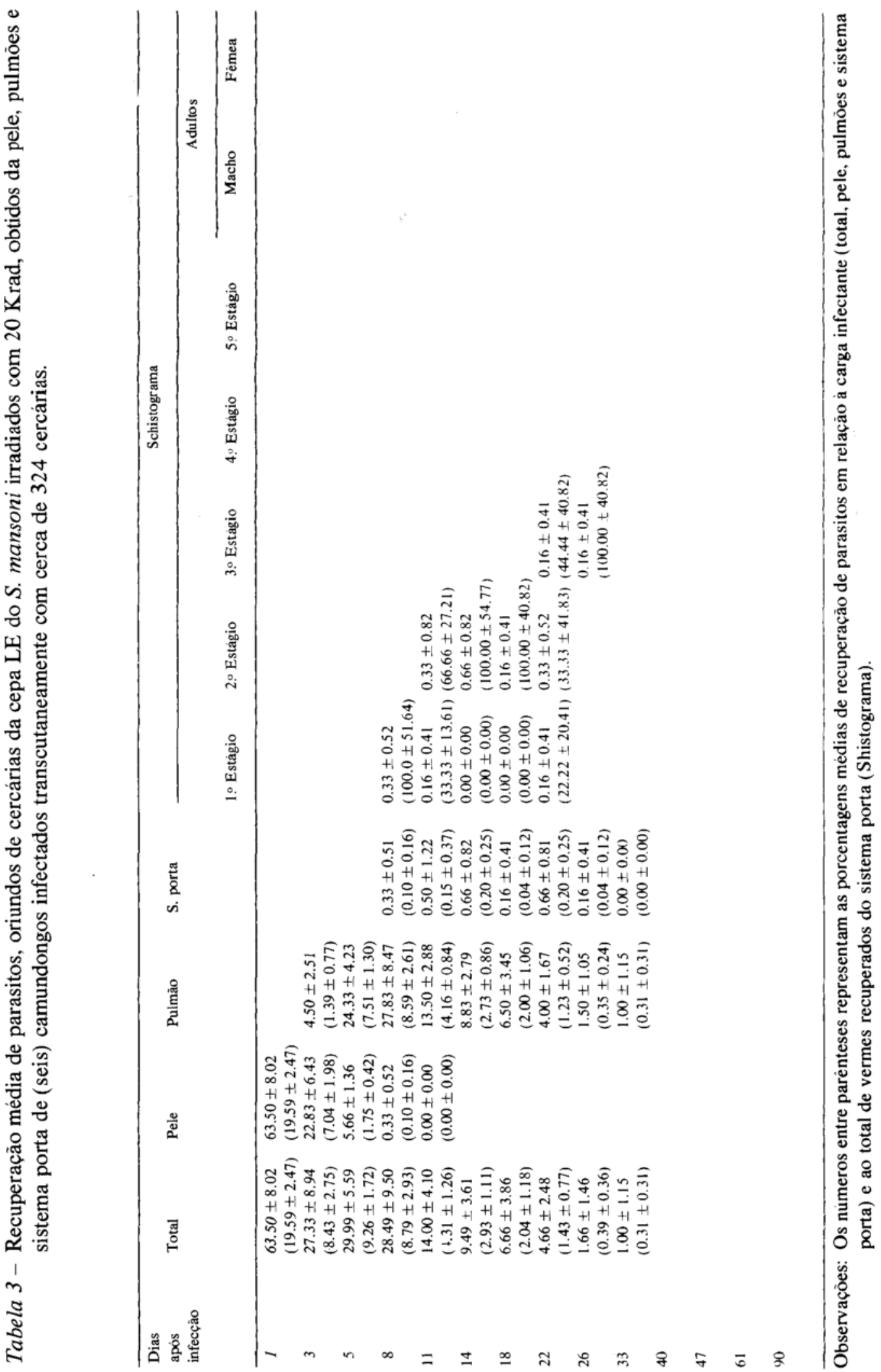




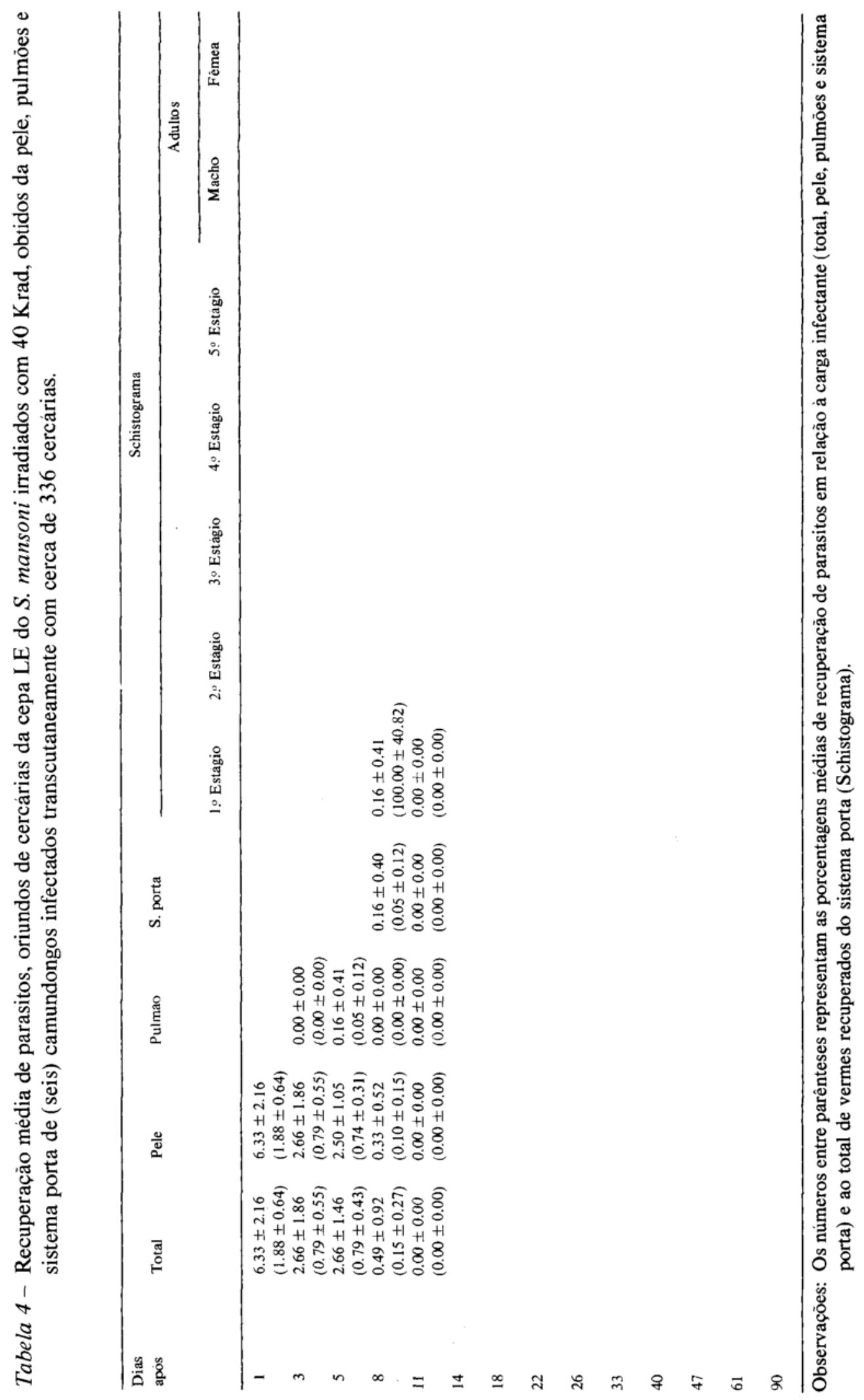




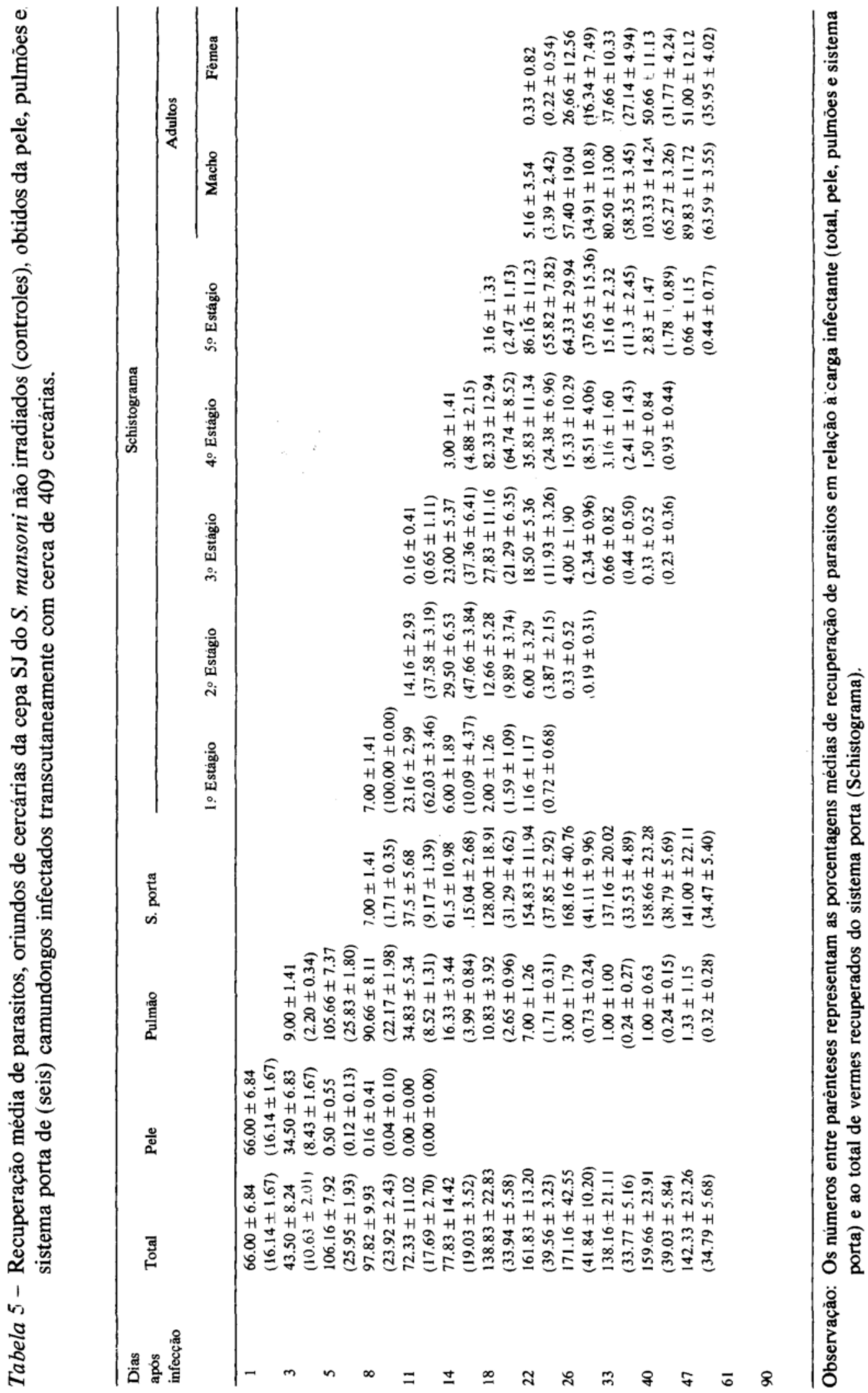




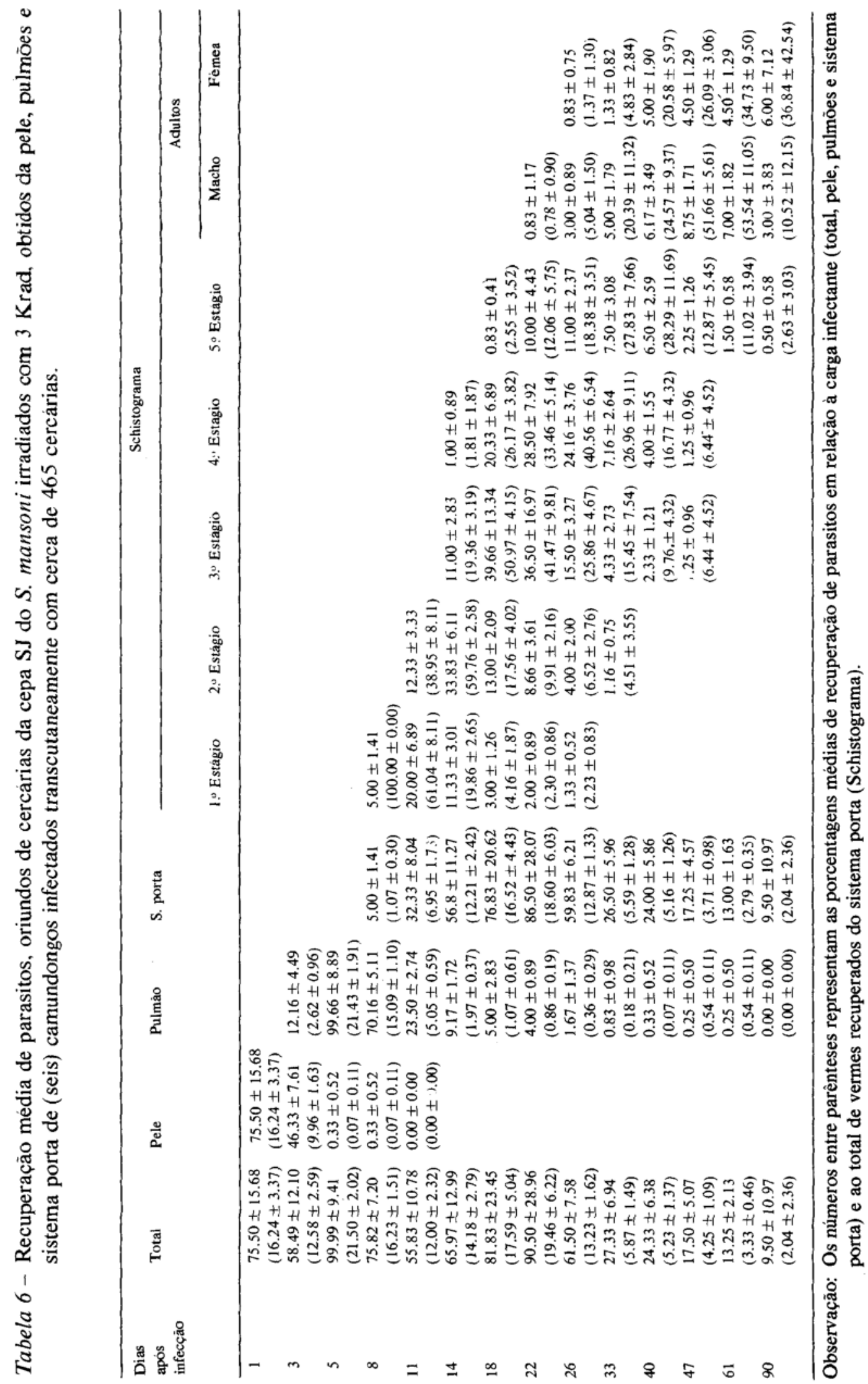




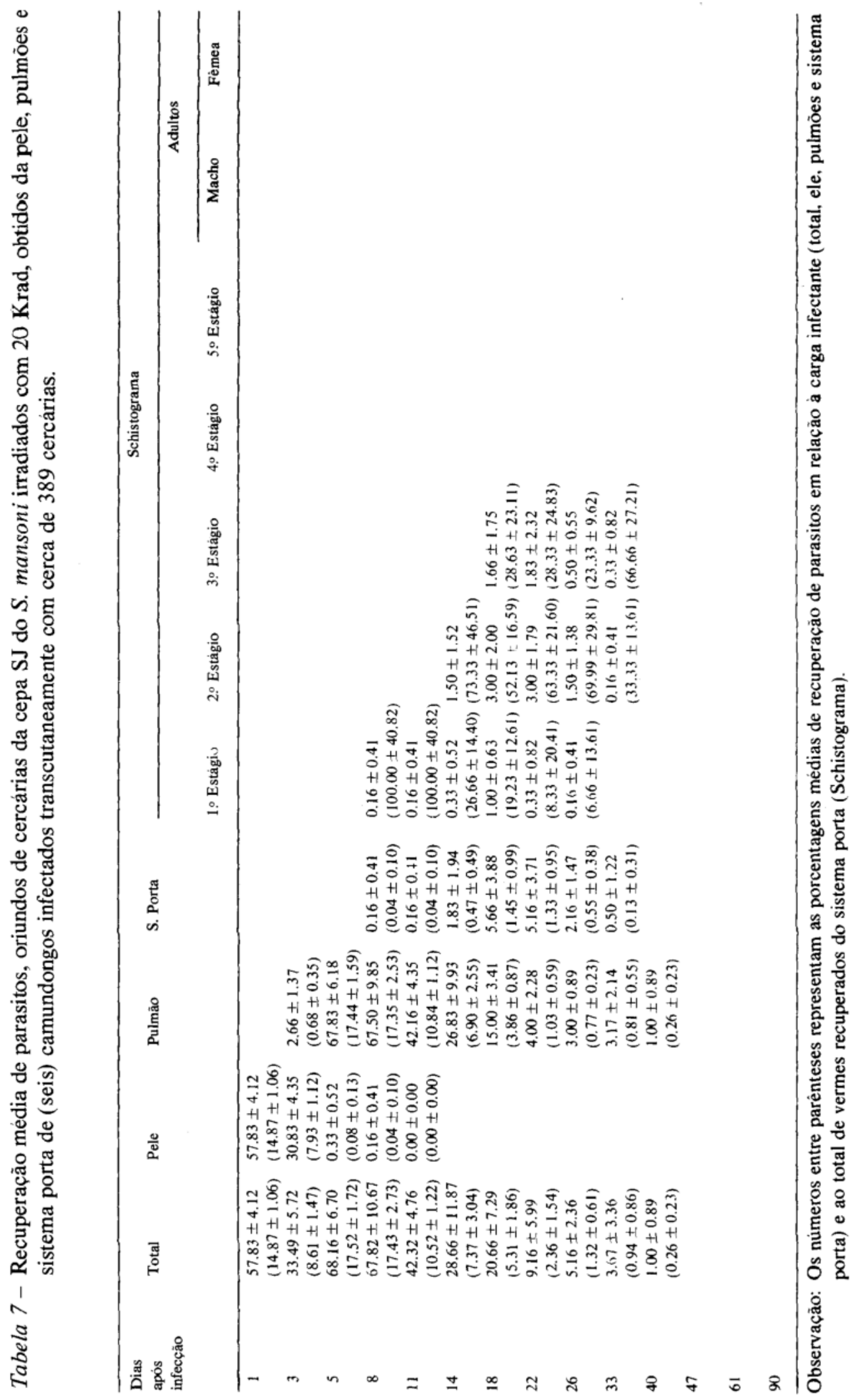




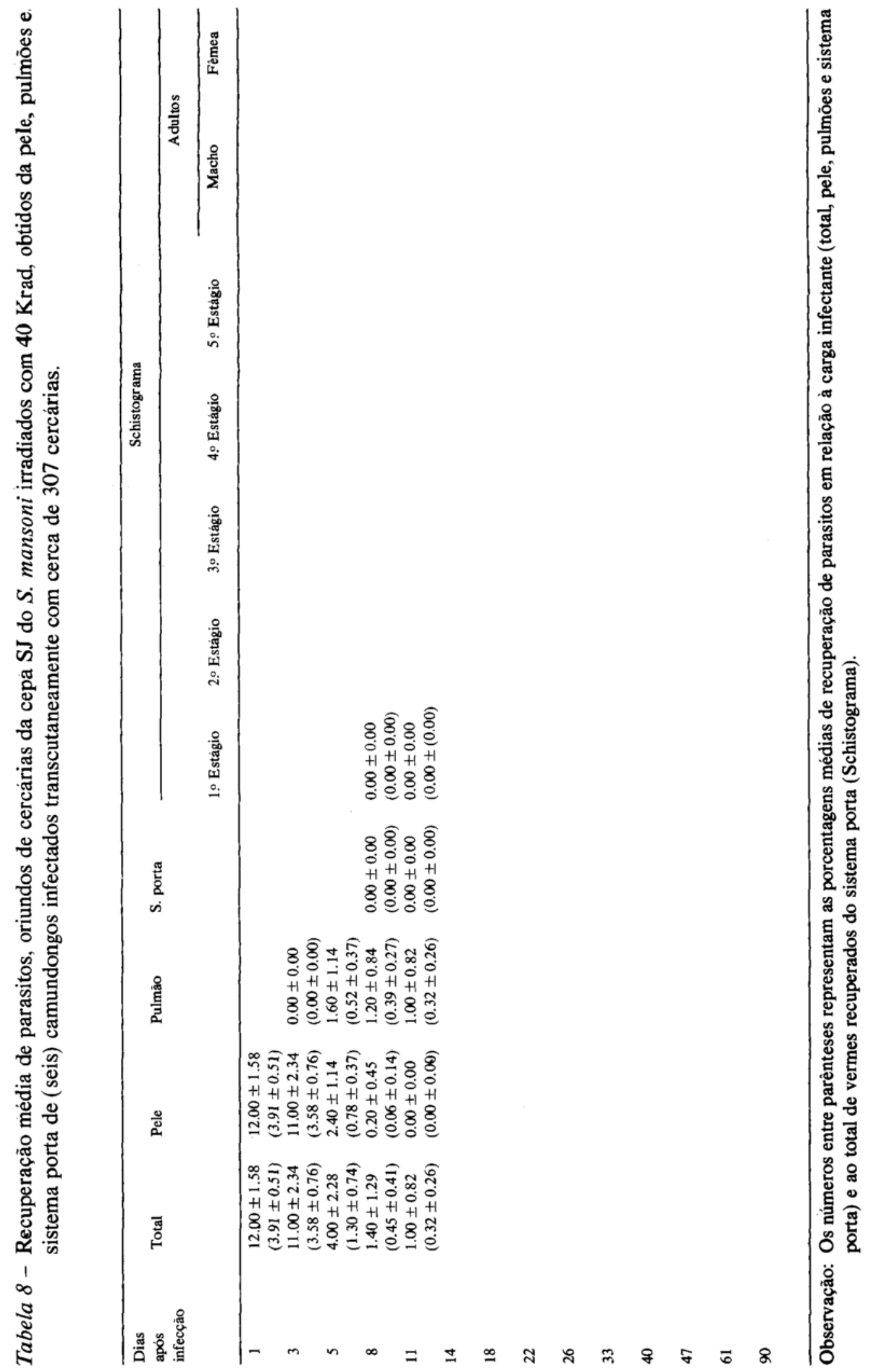


Cardoso GS, Coelho PMZ. Schistosoma mansoni: evoluçao de vermes oriundos de cercárias irradiadas a ni vel de sistema porta, no camundongo. Revista da Sociedade Brasileira de Medicina Tropical 22: 199-210, Out-Dez, 1989.

\section{SUMMARY}

Eight groups of outbred albino mice were infected transcutaneously with cercariae of S. manso$\mathrm{ni}$ (strains $L E$ and $S J$ ) irradiated with either 3, 20 or $40 \mathrm{Krad}$, of gamma radiation from a cobalt-60 bomb and a control non irradiated group. Cercariae irradiated with 20 or $40 \mathrm{Krad}$ failed to develop in the portal system and $3 \mathrm{Krad}$ retarded development. Worms of the $S J$ strain developed more slowlt than the $L E$ strain.

Key-words: Schistosoma mansoni. Irradiated cercariae. Gamma irradiation. Schistogram.

\section{AGRADECIMENTOS}

Os autores agradecem a Adelino Ferreira, Alberto Geraldo dos Santos, Alice Neni Faria, Atenágoras Nascimento Silva, Mauricio Virícimo da Costa e Zenir de Souza pela assistência técnica.

\section{REFERÊNCIAS BIBLIOGRÁFICAS}

1. Barbosa MA, Pellegrino J, Coelho PMZ, Sampaio IBM.
Quantitative aspects of the asynchronism Schistosoma mansoni migration and evolutive in mice. Revista do Instituto de Medicina Tropical de São Paulo, 20:121132, 1978.

2. Dean DA. Schistosoma and related genera: acquired resistance in mice. Experimental Parasitology 55:1-104, 1983.

3. Freitas JR Ritmo de crescimento da Biomphalaria glabrata (Say, 1818). Padronização da técnica de criação. Tese de Doutorado, Universidade Federal de Minas Gerais, Belo Horizonte, 1973.

4. Pellegrino J, Katz N. Infection of baby mice with Schistosoma mansoni: some biological aspects in connection with experimental chemotherapy. Transactions of the Royal Society of Tropical Medicine and Hygiene 63:568-575, 1969.

5. Pellegrino J, Siqueira AF. Técnica de perfusão para colheita de Schistosoma mansoni em cobaias experimentalmente infestadas. Revista Brasileifa de Malariologia e Doenças Tropicals 8:589-597, 1956.

6. Snedecor GW, Cochran WG. Two Way Classification. In: Snedecor GW, Cochran WG (ed). Statistical Methods. End edition, The Iowa State University Press, p. $327-329,1971$. 